\title{
Older Adults in Hospitals: Health Promotion When Hospitalized
}

\author{
Anne-S. Helvik
}

\section{Abstract}

The population of older adults ( $\geq 60$ years) is currently growing. Thus, in the years to come it is expected that a high proportion of patients hospitalized will be in the older age range. In western countries, the proportion of older inpatients is about $40 \%$ in the medical and surgical hospitals units. Older people with illness is vulnerable to both physical and cognitive impairments as well as depression. Therefore, a health-promoting perspective and approach are highly warranted in clinical nursing care of older adults in medical hospitals. This chapter focuses on health promotion related to depressive symptoms, impairment in activities of daily living, and cognitive impairment in older hospitalized adults.

\section{Keywords}

Cognition $\cdot$ Coping $\cdot$ Discharge $\cdot$ Elderly . Functioning $\cdot$ Inpatient $\cdot$ Mood $\cdot$ Screening

\subsection{Introduction}

The increasing proportion of older adults $(\geq 60$ years) [1-3] represents a heterogeneous group of people often characterized by a complex health situation [4], with several diseases and limitations compared to younger adults $[5,6]$. Furthermore, older adults ( $\geq 60$ years) may be more vulnerable for negative health outcomes connected to hospitalization than younger adults. In addition, they may have symptoms of disease that are less typical than for younger adults. Older adults being hospitalized have or may get depressive symptoms, reduced functioning in activities of daily living and/or reduced cognitive functioning, all of which affecting the older individual's coping and health-promoting actions negatively.

To provide good quality nursing care, it is important to have several aspects of care in mind at the same time. In a hospital setting, healthpromoting nursing care improves the medical condition causing hospitalization, strengthens the individual's health-promoting resources, and support well-being and quality of life. Thus, 
focusing on the medical condition(s), promotion of mental health along with cognitive and physical functioning in activities of daily living are equally important.

Health promotion is built on the salutogenesis model proposed by Antonovsky in 1979 [7]. The salutogenic approach to health includes other aspects than the pathogenic model, leading to a more nuanced understanding of health. Salutogeneses includes a shift from solely focusing on the pathogenesis related to the medical reasons for hospitalization and risk factors, toward capabilities and potential of the person. Despite hospitalization and disease, the individuals posess resources which are fundamental for health and well-being. The salutogenic approach to health includes reflection of the patient's life situation, a review of available resources and active adaptation to life stressors, challenges, and a changing situation or environment $[7,8]$. How you cope and adapt to life stressors and challenges are affected of available coping resources. Both general resistant resources (GRR) and sense of coherence (SOC) are of importance [7]. SOC express an individual's ability to comprehend the whole situation, the capacity to use the resources available to move in a health-promoting direction and finding life to be meaningful [7,9]. Thus, the way people are able to perceive structures, create coherence and manage change in a meaningful manner has a central impact on health [8]. Resources available include both internal and external resources [7], and nurses and other health professionals should be valuable resources for health promotion among hospitalized older persons.

\subsection{Methods}

This chapter focuses on hospitalized older adults in general and does not focus on any specific medical condition. The research literature used here has been published in review-based journals reporting results from cross-sectional and longitudinal studies about depression, impairment, and functioning in activities of daily living and cognitive functioning and impairment during and after acutely hospitalization due to medical conditions. The author has published several observational studies focusing on depression, activities of daily living and cognitive functioning during and after acutely hospitalization of older adults [10-17]. Thus, this chapter is based on the authors' former studies, along with previous evidence published up to June 2019. The search terms were: elderly/ older adults/older patients, depression/depressive symptoms, physical functioning/personal functioning/basic functioning/activities of daily living, cognitive functioning/cognitive impairment/ dementia/Alzheimer disease/mild cognitive impairment, and lastly, in patients/hospitalization/ medical ward/geriatric unit and combinations of these terms were also used.

\subsection{Health Promotion During Hospitalization}

Nursing care should contribute to improve the medical condition causing hospitalization as well as promote the patients' health resources. This chapter focuses on health promotion related to depressive symptoms, impairment in activities of daily living and cognitive impairment in older hospitalized adults. The consequences of depression, cognitive impairment, and reduced physical functioning for potential health outcome and well-being are described. Health-promoting care will map existing and limited health resources as basis for care actions. This chapter will also include simple methods to uncover existing and evolving symptoms of depression, cognitive impairment, and limitations of physical activities of daily living.

\subsubsection{Depression}

Depression is a frequent cause of emotional suffering in old age causing negative health consequences such as reduced physical functioning and quality of life [18-20], increased risk of nursing home admission [21], and lower life expectancy $[22,23]$. Depression in old age is also related to higher health care costs [24]. 
Depression, also known as major depressive disorder or clinical depression, is a common and serious mood disorder, which is diagnosed based on specific diagnostic criteria e.g., ICD-10 or DSM-V [25, 26]. Symptoms related to depression are feelings of sadness, hopelessness and loss of interest in activities they once enjoyed, involuntary weight change, sleep disturbance, changes in psychomotor activity, fatigue or loss of energy, feelings of worthlessness or excessive or inappropriate guilt, diminished ability to think or concentrate and recurrent thoughts of death. In accordance to diagnostic criteria, symptoms of (1) depressed mood, or (2) loss of interest or pleasure have to be present to define a person's state as a depression disease [25]. In addition, several of the symptoms mentioned above must be present simultaneously in a 2 weeks period. The severity of the symptoms has to significantly reduce the person's ability of functioning in one's daily living [25].

Older adults may have more uncharacteristic symptoms of depression than younger people. For example, the experience of sadness may be missing, but they may have pronounced medical symptoms such as fatigue, pain, sleeping difficulties, and loss of appetite [27, 28]. In older people depression may be mistaken for dementia, or grief due to losses, as well as a reaction of disease or functional impairment. Depression limits your resilience and resources available to cope with stressors and difficulties as well as to maintain and promote health.

A population-based meta-analysis found the diagnostic pooled prevalence of depression in older adults to be 7\% [29]. Reviews of epidemiological community studies in Europe and worldwide have estimated the prevalence of significant depressive symptoms to be a bit higher and to vary between $8 \%$ and $15 \%$ among older adults $[30,31]$. Poor physical health is a known risk factor for depression [32]. The prevalence of depression or significant depressive symptoms are reported higher in older adults with medical diseases and reduced ability to perform activities of daily living, compared to more healthy older adults [33]. Furthermore, the prevalence of depression is reported higher in older adults being hospitalized [34]. In a review of international studies involving elderly medical inpatients, the prevalence of significant depressive symptoms ranged between $10 \%$ and $73 \%$ [10]. In a Norwegian study of acutely hospitalized older persons coming from rural municipalities, the prevalence of significant depressive symptoms was low (10\%). However, $78 \%$ of those $10 \%$ with significant depressive symptoms had no information in their medical record that they ever had experienced some kind of mental health difficulties, problems or diagnoses of any kind previously in their life [10]. Thus, $78 \%$ of those detected with screening would probable not been uncovered or diagnosed with depression if depression was not systematically screened for at that study. Uncovering existing and evolving symptoms of depression is a necessary step for treatment of the condition.

As said previously, the prevalence of depression is higher in those with medical conditions, is increasing with age [33], and is influenced by gender, ethnicity, place of living, income, and social support [33]. However, hospitalized older adults with reduced ability to perform activities of daily living (ADL), in need of in-home nursing care before hospitalization, and using several prescribed drugs, are more likely to experience depressive symptoms than those without such difficulties or use of drugs [10]. Accordingly, those hospitalized with several and/or considerable health limitations and fewer resources are more likely to experience depressive symptoms. Health personal must be aware of the complex relation between gender, ethnicity, place of living, income, social support, and different health aspects. The older person's total situation as well as his or her background and life experiences are relevant. Health professionals' knowledge about the older adult's thoughts, expectations, wishes and hopes for the stay and future has importance when tailoring care to promote her/his mental state. A person-focused approach with an earnest interest in the person's total situation, including psychological health and mental well-being, includes health-promoting care facilitating perceived meaning-in-life, hope, self-transcendence, and sense of coherence. Moreover, in this context 
health-promoting nursing care includes assessment and awareness of the older person's experience of self-confidence, sense of worthiness/ worthlessness, as well as needs and wishes in the present situation. In all phases of the hospitalization, health-promoting nursing is based on respect of the patient's integrity. Healthpromoting nurse-patient interaction contributes to a sense of being welcome and safe, and to make the situation comprehensible as well as manageable and thereby easing emotional distress. Health-promoting nursing facilitates hope and resilience in the patient and his family.

For older adults, depression may be experienced as being in a vice, with little power of resistance for depressive thoughts, not being able to make peace in life, with limited resilience and reduced ability to experience hope and difficulties finding meaning-in-life [35]. Thus, the salutogenic health processes are impeded. Even so, emotional support as well as respectful attitudes are ground pillars for regaining resilience and meaning-in-life and to boost well-being and health. However, depressive symptoms constrain the old individual's ability to see a positive outcome of the situation. Consequently, identifying depressive symptoms and supporting the older adult's coping resources are essential. This is essential in order to arrange for salutogenic health processes. Even so, depression in older adults may be unrecognized, untreated, and thus reducing the health outcome [36]. This may obstruct health promotion in terms of developing resilience, experiencing coherence, hope, and finding meaning-in-life. Both milder and more severe depressive symptoms may provoke and increase functional limitations in older adults $[12,37]$. Furthermore, the cognitive functioning and quality of life may decrease $[16,38]$, both in a short and long-term perspective. Therefore, the following section focuses on the importance of uncovering depressive symptoms using valid screening tools.

\subsubsection{Uncovering Depressive Symptoms by Use of Screening Tools}

To ask about depression and to screen for depressive symptoms are relevant in order to promote older adults' health while hospitalized. In addition, use of established screening tools may contribute to a joint understanding among health professionals treating and caring for the individual, and be the first step for further examination and eventually a diagnostic workup. Registered nurses may use simple screening tools to reveal depressive symptoms. Several screening tools are available.

The Geriatric Depression Scale for older adults (GDS) [39] is a well-known screening tool and translated to several languages [40, 41]. This tool is used in older adults with minor or no cognitive impairment, but is not suitable among people with dementia [42]. The GDS has several shorter versions; a short version with 15 items [39] is frequently used. Other short versions include four or five items [43, 44]. All versions of the GDS have two response options for each question. The cutoff values indicating clinically relevant symptoms of depression are based on the number of items of the GDS version in use [39, $43,44]$. The GDS screening tools are freely available and deemed suitable for use in hospitals as well as in primary health care.

Another screening tool often used in hospitals is the "Hospital Anxiety and Depression Scale" (HADS) [45] including 14 items with 4 response options (scoring goes from 0 to 3 ). This tool assesses both symptoms of depression and anxiety (7 items within each area) and does not include any questions about physical symptoms related to these conditions. The scale was developed for use in medical hospitals among all ages of adults, including older hospitalized adults. Lately, a study in older adults including persons both with and without poor physical health and need of care assistance found that the cutoff suggested for symptoms indicating depression in the general populations of hospitalized adults $(\geq 8)$ was too high for older adults. In this validation of the HADS, the best cutoff score to indicate a clinical relevant depressive symptom load was 4 [43]. In clinical practice, it is important to note that the score indicating depression may be lower in older adults than for younger adults. Thus, it is important to use screening tools validated for the same type of population. Otherwise, clinically 
relevant depressive symptoms may be underreported and untreated. The items used to assess symptoms of depression and anxiety are found adequate also in older adults [11, 46, 47]. An advantage with use of HADS is that it also assesses anxiety symptoms. Older adults with clinically relevant load of depressive symptoms may also have symptoms of anxiety [48]. HADS is a self-report questionnaire and has several advantages. However, with reduced physical health in combination with reduced cognitive capacity, it may be challenging to answer a questionnaire with four response options at each question. HADS is translated and validated in several languages and settings and have for years been used without charge eff. However, now there may be restricts related to its use [49].

As demonstrated above, the choice of screening tool may depend not only on the preferred use in a care unit, but also on the characteristics of the hospitalized person. The health professionals could preferably know a couple of screening inventories to make the conditions favorable for health promotion.

\subsubsection{Activities of Daily Living (ADL)}

The concept of 'Activities of daily living' (ADL) includes necessary activities to maintain selfcare. ADL consists of basic activities (B-ADL) and more complex actions (I-ADL) that are necessary to be independent of help from others [50]. Even though there are some variations on the definition of B-ADL, this concept normally includes: (1) personal hygiene including bathing/showering, grooming, nail care, and oral care, (2) dressing including the ability to make appropriate clothing decisions and physically dress/undress oneself, (3) eating including having the ability to feed oneself, though not necessarily the capability to prepare food, (4) handling toilet visits including maintaining continence, having both the mental and physical capacity to use a restroom, including the ability to get on and off the toilet and cleaning oneself, and lastly, (5) transferring/mobility including having the ability for moving oneself from seated to standing, getting in and out of bed, and the ability to walk independently from one location to another. The B-ADL is necessarily performed every day.

The more complex actions, named instrumental activities of daily living (I-ADL), are not necessarily required every day, but are related to independent living. The I-ADL includes: (1) using communications technology such as a regular phone, mobile phone, email, or the Internet, (2) using transportation either by driving oneself, arranging rides, or taking public transportation, (3) meal preparation with regard to meal planning, cooking, clean up, storage, and safely use kitchen equipment and utensils, (4) doing shopping and making appropriate food and clothing purchase decisions, (5) housework performance such as doing laundry, washing dishes, dusting, vacuuming, and maintaining a hygienic place of residence, (6) managing medications with regard to taking accurate dosages at the appropriate times, as well as managing re-fills, and finally, (7) managing personal finances with regards to operating within a budget, writing checks, paying bills, and avoiding scams [50].

Concerning functionality, loss of I-ADL is maybe not as noticeable in the beginning as loss of B-ADL, either not for the person self, next of kin and/or health personal. I-ADL functioning generally starts to decline prior to B-ADL functioning. Loss of both I-ADL and B-ADL reduces your ability to maintain self-care and may influence your experience of hope, meaning in life and well-being. Thus, it is important to detect any impairment early and by means of for instance empowerment, to promote individuals' coping, finding new solutions and a new or reinforced understanding of life, hope and meaning, despite that physical health is exposed. Loss of B-ADL functioning may enforce a change of life style followed by lower quality of life and increased mortality [51-57]. In addition, loss of B-ADL will increase health care costs due to care assistance [56-58].

Regardless of the cause of hospitalization, an essential part of nursing is to support and facilitate patients' B-ADL functionality, enhancing self-care during and after the hospitalization and 
thereby to promote health in general. Thus, the nurses focus on assessment, care and treatment and not only on treating the primary cause of hospitalization.

\subsubsection{Decline of B-ADL in Connection with Hospitalization}

Over some years it has been known that functional change in older people is a complex dynamic process where B-ADL may change, both before admission to hospital and during the hospital stay due to their illness and health condition [59] as well as after discharge [12].

The type and degree of B-ADL resources may vary considerably in older adults admitted to a medical hospital [60]. An American study reported that about $30 \%$ of older adults at admission to the medical unit had difficulties with dressing, hygiene, and transferring, and that about $40 \%$ of all patients had experienced a decline in B-ADL within 2 weeks before hospitalization [60].

A health-promotion approach to hospitalized older adults is essential, since a semi-acute or acute illness or condition increases the risk for B-ADL decline [61, 62]. This is the case for older adults, both with and without reduced functioning prior to the hospitalization. A study of more than 2000 older Americans hospitalized in general medical wards reported that about $20 \%$ of the patients had a decline in B-ADL during the hospitalization period [60]; the oldest old revealed the highest loss of B-ADL at discharge [60]. A recent large longitudinal hospital study found three trajectories of B-ADL in older patients admitted to acute medical ward units; (1) functionally decline (17\%), (2) functionally recovering $(41 \%)$, and (3) functionally stable (42\%) over the hospital stay, with a mean of 10.5 days. In this American study, functional decline was explained by nursing and hospital care factors such as less daily care, larger hospital size, and lower care qualifications [63]. Accordingly, adequate time to interact with older hospitalized patients and health-promoting care competency are crucial. Even so, this is not enough. Health-promoting interaction is needed. This means that the health care professionals must engage in the relationship with patients. The professional strives to see, recognize and confirm the patient as the person he is and not only the patient with diagnoses, symptoms, needs and physiological conditions (see Theoretical section). This contributes to a personalized care that is accommodated to the patient's wishes promoting B-ADL and health.

Immobility has long been recognized as a hazard of hospitalization causing loss of body strength and B-ADL functions [61]. Maintaining and improving mobility and body strength as much as possible during hospitalization will improve the patient's ability to perform B-ADLs after discharge. In addition, patients who report unsteadiness while walking at hospital admission are more likely to experience functional decline after a stay in hospital [64]. Furthermore, unsteadiness may contribute to reduced mobility or falls during hospitalization. Thus, it is important to assess unsteadiness in order to give a care adapted to existing resources and support available B-ADL functioning rather than handling consequences of potential new difficulties, illness or impairments.

In general, older people need longer time to recover from illness and $\mathrm{B}-\mathrm{ADL}$ decline. It is reported that among those with a new B-ADL decline during hospitalization, more than onethird needed 3 months or longer after discharge to regain normal B-ADL [52]. Furthermore, a decline in B-ADL is found to relate with mortality; about one fifth of those discharged with a new or additional decline in B-ADL during hospitalization stayed alive only 3 months after hospitalization [52]. Another study reported that the odds to regain normal B-ADL functioning both at 2 and 12 months after hospitalization was reduced by increasing number of B-ADL limitations [65]. A Norwegian observational study of medically hospitalized older adults showed that the mean B-ADL was significantly poorer 1 year after hospitalization compared to the functioning during the hospitalization [12]. In this study, the B-ADL decline 1 year after was explained by poorer baseline B-ADL [12].

A study of more than 500 acutely hospitalized older adults in medical wards reported that those 
with higher decline in B-ADL during hospital stay were more likely to be readmitted to the hospital within 30 days after discharge [66]. Furthermore, a Norwegian study of hospitalized older adults in medical wards found that those with one or more B-ADL difficulties while hospitalized were five times more likely to become nursing home residents within the first year after hospitalization [13]. Thus, in a health-promotion perspective, it is important to promote B-ADL functions while hospitalized. It may contribute to well-being not only in the moment, but also to improved health, well-being, and quality of life over time. Using a health promotion nursing perspective implies that in addition to a focus on supporting and improving B-ADL resources and functioning, the nursing care should be given in a health-promoting manner. Health-promoting interactions are fundamental in nursing care. By use of health-promoting interactions when supporting the patient with his or her B-ADL functioning, health professional may promote an experience of hope and meaning-in-life in the older adults. It may be a hope for managing the situation or hope that with help he or she has the strength to overcome difficulties and experience coherence in life.

Several factors may contribute to a B-ADL decline before, during, and after hospitalization. B-ADL decline may be explained by generally reduced health, loss of weight, chronical disease or multi-morbidity, pain, a high number of drugs taken, and/or visual impairment $[67,68]$. A study revealed that decline in B-ADL after hospitalization, in addition to lower baseline B-ADL, were linked to higher age, reduced cognitive function during and after hospitalization as well as poorer psychological health after hospitalization [12]. The above study demonstrates that B-ADL is one of several areas for health promotion in hospitalized older adults; mental health (depression) and cognitive functioning need nursing attention and health-promoting interventions as well.

Nevertheless, regaining older individuals' B-ADL function requires effective treatment of the underlying conditions. Thus, a further decline of B-ADL during and after hospitalization may be due to ineffective treatment. Furthermore, the health conditions forcing hospitalization may represent the beginning of a health condition that independently of treatment will contribute to a poorer B-ADL functioning. In such cases, healthpromoting interventions by nurses and an interdisciplinary team of health care professionals in the hospital may contribute to reduced speed of the B-ADL decline during, but also after the hospitalization. In a health-promoting approach which is based in a holistic understanding of health, the older individual's situation, available resources and capacity to support self-care and B-ADL must be assessed, and actions taken to sustain B-ADL functioning during hospitalization and thereby contribute to best possible selfcare after the discharge. This can for example be support of unsteadiness, reducing consequences of immobility due to bed rest. Furthermore, it is important to prepare and organize care such as personal hygiene, dressing, toileting, transferring, and other such activities in line with available B-ADL- resources. This may over time be health promoting.

Another reason for B-ADL decline after the hospitalization may be that the older adults themselves do not manage or know how to handle their health problems and their B-ADL deficits after discharge. In a health-promoting perspective, it is important to prepare the patient for the discharge from hospital, to strengthen their coping resources, and contribute to adequate arrangements and support afterwards. An optimal B-ADL function based on the individuals' premises during the hospitalization will also promote health and B-ADL functioning after discharge. For example, studies have found that B-ADL during hospitalization is linked to depression and cognitive function after discharge. Those, with little or no B-ADL deficits during hospitalization have reduced risk of depression and cognitively impairment 1 year after discharge $[14,15]$. The phenomenon of persistent morbidity and functional disability after hospitalization may be labeled as a "post-hospital syndrome" and is accompanied by impaired quality of life of older people [69].

Some care units are organized, and the staff trained, to take care of acutely hospitalized older 
adults. Geriatric care units have for long been known to support and maintain patients' functionality during hospitalization compared to regular units [62]. Regardless of the hospital care unit or ward, health-promoting nursing should be based in a person-oriented approach; this way of interacting with the individual supports the patient's independency and self-care resources, increases hope, meaning, and resilience and thereby facilitates B-ADL performance from admission to discharge [70, 71] (see also Theoretical section). This may, in addition to a well-planned discharge, contribute to well-being and resilience over time. The Acute Care for Elders Unit (ACE) model [70] uses personoriented care, applies a structured process including interdisciplinary teams, and uses systematic screening assessments of B-ADL following clinical guidelines to restore coping resources, resilience, and self-care [70], all of which are important for well-being and quality of life. Three randomized clinical trials using ACE interventions have found reduced B-ADL during hospitalization and reduced risk of nursing home admission among those in ACE units, and furthermore, a somewhat lower cost of hospitalization, due to shorter stay in the group randomized to ACE units [72-74]. The ACE principles could be implemented to improve care of hospitalized older adults, independently of which hospital ward or unit they are admitted to. A step toward including ACE principles is for nurses to be competent in systematic screening of B-ADL.

\subsubsection{Systematically Screening of B-ADL Functioning}

Systematically screening of B-ADL at admission, throughout the hospitalization and at discharge of older hospitalized adults will uncover areas of concern. Previously, the screening tools most often were used in research studies, but clinical experience have shown that systematically use of B-ADL tools improves the quality of nursing care. Nursing assessment is based in a systematic and joint framework to assess change. This framework gives a good basis to minimalize B-ADL decline due to illness, treatment, and hospital stay, and to improve level of functioning. Based in the screening results, adequate nursing actions can be provided. Furthermore, identifying an individual's available B-ADL-resources, possible support and the individuals' will is crucial. Use of screening tools provides a joint framework of the interdisciplinary hospital team for high quality treatment. Consequently, such screening tools will not go out of fashion [50].

Several screening tools assess B-ADL, both short inventories and longer more complex versions exist [75-78]. Such tools have shown to capture small but important changes in an individual's ability to perform B-ADL [50]. Lawton and Brody's scale to assess ability self-care is often used and is among the relatively shorter tools that screen for B-ADL, such as personal hygiene, dressing, toileting, eating, and transferring [75]. This tool is easy to use; a higher score indicates higher B-ADL difficulties. In choosing a screening tool, whether the tool is fitted and validated for the language and culture of the specific country should be considered [70]. The problem in some countries is not a lack of adequate measures, but that there is no national agreement of which measure of B-ADL should be used in ward units and hospitals. This dearth makes it difficult to follow change in B-ADL for individuals with several steps through their treatment chain. It also makes it hard to compare change of B-ADL between institutions and care wards. A consensus about one appropriate tool to measure B-ADL may contribute to quality assurance of treatment and to improvement of care over time.

\subsubsection{Cognitive Functioning}

Decline in cognitive performance is commonly linked to aging $[79,80]$. The cognitive functioning encompasses our ability to receive and process information, remember, learning new stuff, to organize information when we are thinking, using a language and communicate, to write/calculate/draw, have discernment, calculate distances (spatial awareness), take initiative and perform actions, thinking abstract, and to have 
attention. The ability to have attention is also affecting the above areas.

In cognitively intact older adults, an acute medical illness needing hospitalization may lead to reduced cognitive functioning in the acute phase of the disease [81, 82]. The cognitive decline may for some patients be caused by delirium which is an organically caused decline developed over a short period of time, typically hours to days [83]. Delirium is a syndrome encompassing disturbances in attention, consciousness, and cognition [26]. Nurses' knowledge and ability to observe cognitive function and signals of change are essential for the diagnostic process and treatment. Treatment of delirium requires treatment of the underlying disease processes [84]. Nursing care is important to comfort the person with delirium and to avoid additional complications of the disease. Those older adults experiencing delirium has an increased risk of mortality within 12 months [85, 86]. In older hospitalized persons with cognitive decline during the hospitalization, but not delirium, the cognitive function may improve after hospitalization and during the first year after discharge [81, 82]. In a healthpromoting perspective, it is vital to reduce stress related to hospitalization, illness, and new environments. Health-promoting interactions may contribute to reducing the risk of delirium and reduced cognitive functioning, even if the medical illness and biological cause for the illness also are important contributors to reduced cognition.

An increasing number of studies report that older people hospitalized with stroke, heart failure, lung disease, or surgery procedures, have an increased risk for cognitive decline. A review suggested that the hospital processes may partially be responsible for the cognitive decline during and after a hospital stay, beyond the effects of the acute illness(es) [87]. The health-promoting care philosophy and nurse-patient interaction aim to facilitate coping and health resources and thereby supporting cognitive health and wellbeing during and after hospitalization.

Also, some older adults have preexisting cognitive impairment prior to the hospitalization [88], including both mild cognitive impairment (MCI) and dementia. MCI is an intermediate clinical state between normal cognitive aging and dementia, and it precedes and leads to dementia in many cases, but not always $[89,90]$. Dementia is a clinical syndrome causing long term and often gradually loss of cognitive functioning and impairment in activities of daily living [91]. MCI or dementia may not be diagnosed prior to hospitalization or recognized by the older adult him/ her-selves or their next of kin. Despite that preexisting cognitive impairment among older adults may contribute to an overall poorer outcome of the hospitalization, which is also related to an increased risk of delirium [85, 86, 92], preexisting cognitive impairment and limited cognitive resources are often unrecognized by the hospital staff [93]. The use of cognitive screening detecting cognitive limitations and available resources might disclose vulnerability for delirium. Such screening provides information necessary for adequate support and health-promoting actions. Dependent on the context and situation, healthpromoting actions could be to promote sleep and diurnal rhythm, to secure nutrition, to reduce the stressors that may exist in the hospital environment and to minimize side-effects of treatment. Such health-promoting actions can reduce an individual's vulnerability concerning delirium and cognitive decline.

A Norwegian 1-year follow-up study assessed cognitive functioning among older adults without cognitive impairment or dementia. They were screened using the Mini-Mental State Examination (MMSE) [94] and all participants had a score found to be within the normal range (MMSE 24-30) when discharged from a medical hospital unit. Those hospitalized had a wide range of medical diagnoses. This study found that older adults without any known or screened cognitive impairment prior to discharge had a significantly declined function 1 year after [15]. A cognitive decline was found among those with low normal cognitive functioning (MMSE 24-26) as well as in those with high functioning (MMSE 27-30) prior to discharge. ADL impairments, independent of basic or instrumental ADL activities, were associated with an increased risk for reduced cognitive functioning 1 year after hospitalization. This finding was independent of 
age, gender, and severity of the disease among those hospitalized [15]. In line with other studies [87] this study demonstrated that cognitive function is interrelated with ADL functioning. Hence, despite that some cognitive decline results from the actual disease, it is important to counteract decline in the B-ADL functioning, also, among those with normal cognitive functioning. Given that a normal B-ADL among older adults is linked to a better cognitive functioning 1 year after the hospitalization, the importance of maintaining ADL functions seems apparent.

The risk of decline in B-ADL is increased in those with cognitive impairment compared to those without such impairment [12, 95, 96]. Thus, it is essential to counteract limitation of B-ADL functioning due to hospitalization when the patient has cognitive impairment. The nursing care planning needs to consider the disease, as well as both the physical and cognitive functioning resources. Health-promoting nursing utilizes the individual's existing health resources to support well-being and health. In doing so, a care plan is a valuable tool. Also, information collected by screening the patient's cognitive functioning will guide the health-promoting nursing care. Care actions should be based on the patient's resources, both while in hospital and when identifying needs of assistance after discharge from the hospital. Screening of cognitive resources as well as B-ADL functioning, aims to strengthen health resources, compensate for loss of functions, limit decline, and promote well-being. After discharge each patient should be provided the best premises to cope at home, as well as receiving care and support at home, in a rehabilitation unit or in a care facility. Summarized, screening of cognitive functioning represents a fundamental basis for health-promoting care during a hospital stay as well as in supporting the individual to cope at home after hospitalization.

\subsubsection{Systematic Screening of Cognitive Functioning}

A reliable assessment of patients' cognitive functioning cannot be based on a single clinical observation and/or the patient's self-report. Therefore, it is important to routinely screen older adults' cognitive functioning when hospitalized. Most often, the screened areas are memory (short term and working), attention, concentration, orientation, language skills, interpret sense impressions, ability to follow simple instructions, and processing information [94, 97]. However, the different screening tools differ concerning which cognitive areas they include. Two commonly used screening tools are Montreal Cognitive Assessment tool (MoCA) [97] and Mini-Mental State Examination (MMSE) [94]. MoCA is a suitable measure assessing persons with mild cognitive complaints [97] and a mild degree of dementia. The maximum sum score of MoCA is 30 points, where higher scores indicate a better cognitive functioning. A score between 26 and 30 points indicates normal cognitive functioning [97].

The Mini-Mental Status Examination (MMSE) is frequently used to assess cognitive functioning both for clinical and research purposes. The MMSE is a 30-point scale, where higher scores indicate a better cognitive functioning [10]. While used for screening purposes, a score below 20 indicates cognitive impairment, whereas the interval between 20 and 24 indicates a mild cognitive impairment. Even so, the reported cutoff points for abnormality have varied considerably [98]. However, it is important to be aware that the MMSE is not a diagnostic tool, but a screening tool that indicates whether an individual's cognitive functioning needs a special attention during the hospital stay.

The most frequently noted disadvantage of the MMSE relates to its lack of sensitivity to mild cognitive impairment [99]. Another disadvantage of the MMSE is that the score may be affected by demographic factors; age and education exert the greatest effect [100]. In addition, the MMSE is protected by copyright and authorized use of the test is linked to costs [101-103] which has forced clinicians to use other tests [98]. Nevertheless, independently of which screening tool one chose it is important to gain knowledge and practice before the tool is used in clinical settings or for research purposes. The mentioned screening tools are easy to use and implement; thus, utilizing such 
screening tools provides a common understanding and reference for cognitive functioning promoting systematic care and treatment.

\subsection{Conclusion - Health- Promoting Assets and Actions}

Older adults are often vulnerable for complications and loss of coping resources when hospitalized. While facing physical disease, good coping resources such as sense of coherence and trusting one's coping capacity is important for well-being and perceived health [17]. Thus, care supporting both improvement of the medical condition contributing to the hospitalization and coping resources is important.

In this chapter, we have been looking at three factors related to high age that are contributing to vulnerability when hospitalized: depression, B-ADL decline, and cognitive impairment. These conditions limit coping resources, well-being, and health.

Clinically significant depressive symptoms need to be uncovered and treated, if not they may have negative consequences for the treatment, cognitive functioning and B-ADL functioning. Thus, a general assessment should preferably include screening of depressive symptoms.

Older adults in needs of assistance to ensure B-ADL functioning, such as personal hygiene, toileting, walking, eating, etc., should be given assistance supporting present resources and abilities. To do so, the health professionals need to observe the level of functioning and develop a plan for how they can support the patient's health resources and compensate for lacking abilities.

The utilization of tools assessing cognitive functioning, depressive symptoms, and B-ADL functioning will equip health professionals with a common understanding which will contribute to a systematic approach to care in a healthpromoting way.

Additionally, there are several other health conditions important for coping and health promotion during and after hospitalization. In older adults, securing or maintaining a healthy pattern of sleep and proper nutrition during the hospital stay are vital. Furthermore, existential and religious needs might be actualized due to hospitalization and declining health. While hospitalized, family and social resources available to support living at home after hospitalization needs to be mapped. Thus, it is imperative to prepare, plan, and organize the transition to home or to a care home in advance of the discharge. However, these areas are not covered in this chapter.

\section{Take Home Messages}

- Depression is a frequent cause of emotional suffering in old age causing negative health consequences.

- Unrecognized and untreated depression may obstruct health promotion, thus, uncovering depressive symptoms using valid screening tools is important.

- In older adults, a hospitalization increases the risk for decline of physical functioning and ADL.

- Based in a holistic understanding of health, the older individual's situation, available resources and capacity to support self-care and ADL must be assessed, and actions taken to sustain ADL functioning during hospitalization.

- In older adults, an acute medical illness needing hospitalization may lead to reduced cognitive functioning in the acute phase of the disease.

- Limited cognitive resources are often unrecognized by the hospital staff if not screened for.

- Common understanding of available cognitive, mental and physical resources in older adults may contribute to a systematic approach to care in a health-promoting way.

\section{References}

1. Syse A, Pham D, Keilman N. Befolkningsframskrivinger 2016-2100: Dødelighet og levealder. In: Økonomiske analyser 3/2016. Oslo: Statistisk sentralbyrå; 2016.

2. Vincent GK, Velkoff VA. The next four decades: the older population in the United States: 2010-2050. 
Washington, DC: United States Census Bureau; 2010. p. 15. https://www.census.gov/content/dam/ Census/library/publications/2010/demo/p25-113.

3. US Centers for Disease Control and Prevention. Number, percent distribution, rate, days of care with average length of stay, and standard error of discharges from short-stay hospitals, by sex and age: United States. 2010. https://www.cdc.gov/nchs/data/ nhds/2average/2010ave2_ratesexage.pdf Accessed 20 Aug 2019.

4. SAMDATA2013 Spesialisthelsetjenesten. Helsedirektoratet. 2014. https://www.helsedirektoratet.no/search?searchquery=SAMDATA $\% 202013$.

5. Rø, O. Gamle i sykehus. Innlagte 75 år og over i medisinsk avdeling 1998. In: Helsetlisynets utredningsserie; 7/99; 1999.

6. Marengoni A, et al. Prevalence of chronic diseases and multimorbidity among the elderly population in Sweden. Am J Public Health. 2008;98(7):1198-200.

7. Antonovsky A. Unraveling the mystery of health. San Francisco: Jossey-Bass; 1987.

8. Eriksson M, Lindström B. A salutogenic interpretation of the Ottawa charter. Health Promot Int. 2008;23(2):190-9.

9. Lindstrom B, Eriksson M. Salutogenesis. J Epidemiol Community Health. 2005;59(6):440-2.

10. Helvik AS, Skancke RH, Selbaek G. Screening for depression in elderly medical inpatients from rural area of Norway: prevalence and associated factors. Int J Geriatr Psychiatry. 2010;25(2):150-9.

11. Helvik AS, et al. A psychometric evaluation of the hospital anxiety and depression scale for the medically hospitalized elderly. Nord J Psychiatry. 2011;65:338-44.

12. Helvik AS, Selbaek G, Engedal K. Functional decline in older adults one year after hospitalization. Arch Gerontol Geriatr. 2013;57(3):305-10.

13. Helvik AS, et al. Nursing home admission during the first year after hospitalization - the contribution of cognitive impairment. PLoS One. 2014;9(1):e86116.

14. Helvik AS, Engedal K, Selbaek G. Depressive symptoms among the medically hospitalized older individuals -- a 1-year follow-up study. Int J Geriatr Psychiatry. 2013;28(2):199-207.

15. Helvik AS, Selbaek G, Engedal K. Cognitive decline one year after hospitalization in older adults without dementia. Dement Geriatr Cogn Disord. 2012;34(3-4):198-205.

16. Helvik AS, Engedal K, Selbaek G. The quality of life and factors associated with it in the medically hospitalised elderly. Aging Ment Health. 2010;14(7):861-9.

17. Helvik AS, et al. Factors associated with perceived health in elderly medical inpatients: a particular focus on personal coping recourses. Aging Ment Health. 2012;16(6):795-803.

18. Sivertsen H, et al. Depression and quality of life in older persons: a review. Dement Geriatr Cogn Disord. 2015;40(5-6):311-39.
19. Charlson ME, et al. Outcomes of community-based social service interventions in homebound elders. Int J Geriatr Psychiatry. 2008;23(4):427-32.

20. Reid MC, et al. Depressive symptoms as a risk factor for disabling back pain in community-dwelling older persons. J Am Geriatr Soc. 2003;51(12):1710-7.

21. Lohman MC, Mezuk B, Dumenci L. Depression and frailty: concurrent risks for adverse health outcomes. Aging Ment Health. 2017;21(4):399-408.

22. Moise N, et al. Observational study of the differential impact of time-varying depressive symptoms on all-cause and cause-specific mortality by health status in community-dwelling adults: the REGARDS study. BMJ Open. 2018;8(1):e017385.

23. Aziz R, Steffens DC. What are the causes of late-life depression? Psychiatr Clin North Am. 2013;36(4):497-516.

24. Katon WJ, et al. Increased medical costs of a population-based sample of depressed elderly patients. Arch Gen Psychiatry. 2003;60(9):897-903.

25. WHO. International statistical classification of diseases and related health problems, 10th Revision. Geneva: World Health Organisation; 2016. https:// icd.who.int/browse10/2016/en

26. Arlington V. Diagnostic and statistical manual of mental disorders : DSM-5 (Fifth ed.). Washington, DC: American Psychiatric Association; 2013.

27. Gallo JJ, Rabins PV. Depression without sadness: alternative presentations of depression in late life. Am Fam Physician. 1999;60(3):820-6.

28. Carpenter L, Winnett A. Depression in hospitalized elderly people. Br J Hosp Med (Lond). 2014;75(8):C126-8.

29. Luppa M, et al. Age- and gender-specific prevalence of depression in latest-life--systematic review and meta-analysis. J Affect Disord. 2012;136(3):212-21.

30. Copeland JR, et al. Depression in Europe. Geographical distribution among older people. Br J Psychiatry. 1999;174:312-21.

31. Rosenvinge BH, Rosenvinge JH. Forekomst av depresjon - systematisk oversikt over 55 prevalens studier fra 1990-2001. [Occurrence of depression in the elderly--a systematic review of 55 prevalence studies from 1990-2001. In Norwegian]. Tidsskr Nor Laegeforen. 2003;123(7):928-9.

32. Blazer DG. Depression in late life: review and commentary. J Gerontol A Biol Sci Med Sci. 2003;58(3):249-65.

33. Stordal E. Aspects of the epidemiology of depression based on self-rating in a large general health study (The HUNT-2 study). Trondheim: Department of Neuroscience, Faculty of Medicine, University of Science and Technology; 2005.

34. Alexopoulos GS, et al. Assessment of late life depression. Biol Psychiatry. 2002;52(3): 164-74.

35. Bjørkløf GH, et al. Being stuck in a vice: the process of coping with severe depression in late life. Int $\mathbf{J}$ Qual Stud Health Well-being. 2015;10:27187. 
36. Frasure-Smith N, et al. Social support, depression, and mortality during the first year after myocardial infarction. Circulation. 2000;101(16):1919-24.

37. Covinsky KE, et al. Relation between symptoms of depression and health status outcomes in acutely ill hospitalized older persons. Ann Intern Med. 1997;126(6):417-25.

38. Kørner EA. Forekomst av depression hos ældre over 65 år i Karlebo kommune. [Prevalence of depression in elderly over 65 years in Karlebo Municipality. In Danish]. København: Foreningen af Danske Lægestuderendes Forlag; 1998.

39. Sheikh J, Yesavage J. Geriatric depression scale (GDS): recent evidence and development of a shorter version. In: Clinical gerontology: a guide to assessment and intervention. Philadelphia: The Haworth Press; 1986. p. 165-73.

40. Berentsen VD, Schirmer H. Depresjon hos geriatriske pasienter. In: Sosial og Helsedepartementet og Statens Helsetilsyns utviklingsprogram om alderspykiatri, Rapport 2; 1995.

41. Baker FM, Espino DV. A Spanish version of the geriatric depression scale in Mexican-American elders. Int J Geriatr Psychiatry. 1997;12(1):21-5.

42. Burke WJ, et al. Use of the geriatric depression scale in dementia of the Alzheimer type. J Am Geriatr Soc. 1989;37(9):856-60.

43. Eriksen S, et al. The validity of the hospital anxiety and depression scale and the geriatric depression scale-5 in home-dwelling old adults in Norway. J Affect Disord. 2019;256:380-5.

44. Weeks SK, et al. Comparing various short-form geriatric depression scales leads to the GDS-5/15. J Nurs Scholarsh. 2003;35(2):133-7.

45. Montgomery S, Asberg M. A new depression scale designed to be sensitive to change. Br J Psychiatry. 1979;134:382-9.

46. Haugan G, Drageset J. The hospital anxiety and depression scale-dimensionality, reliability and construct validity among cognitively intact nursing home patients. J Affect Disord. 2014;165:8-15.

47. Djukanovic I, Carlsson J, Arestedt K. Is the hospital anxiety and depression scale (HADS) a valid measure in a general population 65-80 years old? A psychometric evaluation study. Health Qual Life Outcomes. 2017;15(1):193.

48. Beattie E, Pachana NA, Franklin SJ. Double jeopardy: comorbid anxiety and depression in late life. Res Gerontol Nurs. 2010;3(3):209-20.

49. Hospital anxiety and depression scale (HADS); 2019.

50. Bennett JA. Activities of daily living. Old-fashioned or still useful? J Gerontol Nurs. 1999;25(5):22-9.

51. Inouye SK, et al. Importance of functional measures in predicting mortality among older hospitalized patients. JAMA. 1998;279(15):1187-93.

52. Boyd CM, et al. Recovery of activities of daily living in older adults after hospitalization for acute medical illness. J Am Geriatr Soc. 2008;56(12):2171-9.
53. Buurman BM, et al. Geriatric conditions in acutely hospitalized older patients: prevalence and oneyear survival and functional decline. PLoS One. 2011;6(11):e26951.

54. Fortinsky RH, et al. Effects of functional status changes before and during hospitalization on nursing home admission of older adults. J Gerontol A Biol Sci Med Sci. 1999;54(10):M521-6.

55. WHO. International classification of functioning, disability and health. Geneva: World Health Organization; 2001. p. 251.

56. Campbell SE, Seymour DG, Primrose WR. A systematic literature review of factors affecting outcome in older medical patients admitted to hospital. Age Ageing. 2004;33(2):110-5.

57. Millan-Calenti JC, et al. Prevalence of functional disability in activities of daily living (ADL), instrumental activities of daily living (IADL) and associated factors, as predictors of morbidity and mortality. Arch Gerontol Geriatr. 2010;50(3):306-10.

58. Chuang KH, et al. Diagnosis-related group-adjusted hospital costs are higher in older medical patients with lower functional status. J Am Geriatr Soc. 2003;51(12):1729-34.

59. Hirsch $\mathrm{CH}$, et al. The natural history of functional morbidity in hospitalized older patients. J Am Geriatr Soc. 1990;38(12):1296-303.

60. Covinsky KE, et al. Loss of independence in activities of daily living in older adults hospitalized with medical illnesses: increased vulnerability with age. J Am Geriatr Soc. 2003;51(4):451-8.

61. Creditor MC. Hazards of hospitalization of the elderly. Ann Intern Med. 1993;118(3):219-23.

62. Zelada MA, Salinas R, Baztan JJ. Reduction of functional deterioration during hospitalization in an acute geriatric unit. Arch Gerontol Geriatr. 2009;48(1):35-9.

63. Palese A, et al. Hospital-acquired functional decline in older patients cared for in acute medical wards and predictors: findings from a multicentre longitudinal study. Geriatr Nurs. 2016;37(3):192-9.

64. Lindenberger EC, et al. Unsteadiness reported by older hospitalized patients predicts functional decline. J Am Geriatr Soc. 2003;51(5):621-6.

65. Wu AW, et al. Predicting functional status outcomes in hospitalized patients aged 80 years and older. J Am Geriatr Soc. 2000;48(5 Suppl): S6-15.

66. Tonkikh O, et al. Functional status before and during acute hospitalization and readmission risk identification. J Hosp Med. 2016;11(9):636-41.

67. Stuck AE, et al. Risk factors for functional status decline in community-living elderly people: a systematic literature review. Soc Sci Med. 1999;48(4):445-69.

68. Vermeulen $\mathrm{J}$, et al. Predicting ADL disability in community-dwelling elderly people using physical frailty indicators: a systematic review. BMC Geriatr. 2011;11:33. 
69. Krumholz HM. Post-hospital syndrome--an acquired, transient condition of generalized risk. $\mathrm{N}$ Engl J Med. 2013;368(2):100-2.

70. Palmer RM. The acute care for elders unit model of care. Geriatrics (Basel). 2018;3(3):59.

71. Flood KL, et al. Acute Care for Elders (ACE) Team Model of Care: a clinical overview. Geriatrics (Basel). 2018;3(3):50.

72. Barnes DE, et al. Acute care for elders units produced shorter hospital stays at lower cost while maintaining patients' functional status. Health Aff (Millwood). 2012;31(6):1227-36.

73. Landefeld CS, et al. A randomized trial of care in a hospital medical unit especially designed to improve the functional outcomes of acutely ill older patients. N Engl J Med. 1995;332(20):1338-44.

74. Counsell SR, et al. Effects of a multicomponent intervention on functional outcomes and process of care in hospitalized older patients: a randomized controlled trial of acute care for elders (ACE) in a community hospital. J Am Geriatr Soc. 2000;48(12):1572-81.

75. Lawton MP, Brody EM. Assessment of older people: self-maintaining and instrumental activities of daily living. Gerontologist. 1969;9(3):179-86.

76. Mahoney F, Barthel D. FUNCTIONAL EVALUATION: THE BARTHEL INDEX. Md State Med J. 1965;14:61-5.

77. Katz S, et al. Progress in development of the index of ADL. Gerontologist. 1970;10(1):20-30.

78. Buurman BM, et al. Variability in measuring (instrumental) activities of daily living functioning and functional decline in hospitalized older medical patients: a systematic review. J Clin Epidemiol. 2011;64(6):619-27.

79. Zuccala G, et al. The effects of cognitive impairment on mortality among hospitalized patients with heart failure. Am J Med. 2003;115(2):97-103.

80. Chodosh J, et al. Cognitive decline in highfunctioning older persons is associated with an increased risk of hospitalization. J Am Geriatr Soc. 2004;52(9):1456-62.

81. Inouye SK, et al. Recoverable cognitive dysfunction at hospital admission in older persons during acute illness. J Gen Intern Med. 2006;21(12): 1276-81.

82. Lindquist LA, et al. Improvements in cognition following hospital discharge of community dwelling seniors. J Gen Intern Med. 2011;26(7):765-70.

83. Ahmed S, Leurent B, Sampson EL. Risk factors for incident delirium among older people in acute hospital medical units: a systematic review and metaanalysis. Age Ageing. 2014;43(3):326-33.

84. Wong CL, et al. Does this patient have delirium?: value of bedside instruments. JAMA. 2010;304(7):779-86.
85. Israni J, et al. Delirium as a predictor of mortality in US Medicare beneficiaries discharged from the emergency department: a national claims-level analysis up to 12 months. BMJ Open. 2018;8(5):e021258.

86. McCusker J, et al. Delirium predicts 12-month mortality. Arch Intern Med. 2002;162(4):457-63.

87. Dasgupta M. Cognitive impairment in hospitalized seniors. Geriatrics (Basel). 2016;1(1):4.

88. Pisani MA, McNicoll L, Inouye SK. Cognitive impairment in the intensive care unit. Clin Chest Med. 2003;24(4):727-37.

89. Thompson SA, Hodges JR. Mild cognitive impairment: a clinically useful but currently ill-defined concept? Neurocase. 2002;8(6):405-10.

90. Petersen RC. Clinical practice. Mild cognitive impairment. N Engl J Med. 2011;364(23):2227-34.

91. Burns A, Iliffe S. Dementia. BMJ. 2009;338:b75.

92. Kukreja D, Gunther U, Popp J. Delirium in the elderly: current problems with increasing geriatric age. Indian J Med Res. 2015;142(6):655-62.

93. Pisani MA, et al. Underrecognition of preexisting cognitive impairment by physicians in older ICU patients. Chest. 2003;124(6):2267-74.

94. Folstein MF, Folstein SE, McHugh PR. "Mini-mental state". A practical method for grading the cognitive state of patients for the clinician. J Psychiatr Res. 1975;12(3):189-98.

95. Helvik AS, et al. A 52 month follow-up of functional decline in nursing home residents - degree of dementia contributes. BMC Geriatr. 2014;14(1):45.

96. Helvik A-S, et al. A 36-month follow-up of decline in activities of daily living in individuals receiving domiciliary care. BMC Geriatr. 2015;15:47. https:// doi.org/10.1186/s12877-015-0047-7.

97. Nasreddine ZS, et al. The Montreal Cognitive Assessment, MoCA: a brief screening tool for mild cognitive impairment. J Am Geriatr Soc. 2005;53(4):695-9.

98. Holsinger T, et al. Does this patient have dementia? JAMA. 2007;297(21):2391-404.

99. Arevalo-Rodriguez I, et al. Mini-Mental State Examination (MMSE) for the detection of Alzheimer's disease and other dementias in people with mild cognitive impairment (MCI). Cochrane Database Syst Rev, 2015;(3):CD010783.

100. Crum RM, et al. Population-based norms for the Mini-Mental State Examination by age and educational level. JAMA. 1993;269(18):2386-91.

101. Powsner S, Powsner D. Cognition, copyright, and the classroom. Am J Psychiatry. 2005;162(3):627-8.

102. Folstein M, Folstein S, McHugh P. Mini-Mental State Examination. Psychological assessment resources, Inc. https://web.archive.org/web/20070929001727/ http://www.minimental.com/.

103. de Silva V, Hanwella R. Why are we copyrighting science? BMJ. 2010;341:c4738. 
Open Access This chapter is licensed under the terms of the Creative Commons Attribution 4.0 International License (http://creativecommons.org/licenses/by/4.0/), which permits use, sharing, adaptation, distribution and reproduction in any medium or format, as long as you give appropriate credit to the original author(s) and the source, provide a link to the Creative Commons license and indicate if changes were made.

The images or other third party material in this chapter are included in the chapter's Creative Commons license, unless indicated otherwise in a credit line to the material. If material is not included in the chapter's Creative Commons license and your intended use is not permitted by statutory regulation or exceeds the permitted use, you will need to obtain permission directly from the copyright holder.

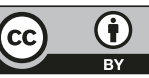

